\title{
Early postoperative anastomotic hemorrhage after gastrectomy for gastric cancer
}

\author{
Yutaka Tanizawa ${ }^{1}$, Etsuro Bando ${ }^{1}$, Tailchi Kawamura ${ }^{1}$, Masanori Tokunaga ${ }^{1}$, Hiroyuki Ono ${ }^{2}$ \\ and MASANORI TERASHIMA ${ }^{1}$ \\ ${ }^{1}$ Division of Gastric Surgery, Shizuoka Cancer Center, 1007 Shimonagakubo, Nagaizumi-cho, Shizuoka 411-8777, Japan \\ ${ }^{2}$ Division of Endoscopy, Shizuoka Cancer Center, Shizuoka, Japan
}

\begin{abstract}
Background. Postoperative anastomotic hemorrhage is a relatively rare complication, but it is lethal if not treated immediately.

Methods. Of 1400 patients with gastric cancer who underwent gastrectomy between September 2002 and December 2007, postoperative anastomotic hemorrhage was observed in 6 patients. The surgical procedures, bleeding sites, methods of hemostasis, and clinical courses of these 6 patients were analyzed.

Results. Of the 1400 patients, 878, 72, and 450 underwent distal, proximal, and total gastrectomy, respectively. The bleeding sites were as follows: transection line of the stomach using a linear stapler $(n=1)$; gastroduodenostomy using a circular stapler $(n=3)$; gastrojejunostomy by hand-suture ( $n$ $=1)$; and esophagojejunostomy using a circular stapler $(n=$ 1). Five patients achieved complete hemostasis with endoscopic treatment. One patient underwent re-operation for anastomotic hemorrhage without endoscopic therapy. Two patients had delayed gastric emptying, and one patient developed an intraabdominal abscess after hemostatic treatment. Conclusion. Postoperative anastomotic hemorrhage is an infrequent but potentially life-threatening complication. Endoscopy appears to be useful for both the confirmation of bleeding and therapeutic intervention.
\end{abstract}

Key words Anastomosis · Gastrectomy · Gastric cancer · Hemorrhage $\cdot$ Postoperative complications

\section{Introduction}

Anastomotic leakage, stricture, and hemorrhage are major complications related to anastomosis after gastrectomy. Compared with leakage and stricture, anastomotic hemorrhage is rare and usually self-limited [1-9]. However, massive bleeding is lethal if not treated imme-

Offprint requests to: Y. Tanizawa

Received: September 7, 2009 / Accepted: December 2, 2009 diately. Many investigators have reported the complications associated with anastomosis, but there are few reports that focused on anastomotic hemorrhage as an early complication following gastrectomy for gastric cancer $[10,11]$. The purpose of the present study was to determine the incidence of anastomotic hemorrhage and to analyze the surgical procedures, bleeding sites, methods of hemostasis, and clinical courses of the patients with this complication.

Subjects, materials, and methods

The subjects included 1467 consecutive patients with gastric cancer who underwent gastrectomy between September 2002 and December 2007. Among them, 67 patients underwent resection of multiple organs because of synchronous, multiple, primary cancers other than those of the stomach, and were thus excluded from data analysis. Therefore, 1400 patients were enrolled in this study. Anastomotic hemorrhage was observed in 6 patients $(0.4 \%)$. In this study, anastomotic hemorrhage was defined as massive bleeding that needed endoscopic or surgical intervention for hemostasis. Patients with minor bleeding that was treated conservatively were excluded. In addition, patients requiring hemostasis procedures during operation because anastomotic bleeding was immediately recognized were excluded.

The type of gastrectomy, the reconstruction procedures, methods of anastomosis, bleeding sites, methods of treatment, and clinical courses in the postoperative period were analyzed for the six patients with anastomotic hemorrhage.

JMP version 8.0 for Windows (SAS Institute, Cary, NC, USA) was used for all statistical analyses. The $\chi^{2}$ test was used to evaluate differences in proportions, and the Mann-Whitney $U$-test was used to evaluate continuous variables. All data are expressed as means \pm SD. A level of $P<0.05$ was taken as significant. 


\section{Results}

\section{Bleeding site}

The surgical procedures and the incidence of anastomotic bleeding are shown in Table 1 . Of the 1400 patients, 878,72 , and 450 underwent distal, proximal, and total gastrectomy, respectively. Overall, 454 patients underwent esophagojejunostomy using a circular stapler after total gastrectomy or proximal gastrectomy, and only 1 patient underwent a hand-sewn esophagojejunostomy; 67 patients underwent esophagogastrostomy using circular stapler after proximal gastrectomy; 502 patients underwent gastroduodenostomy or gastrojejunostomy using a circular stapler, and 48 patients underwent gastrojejunostomy using a linear stapler; 328 patients underwent a hand-sewn anastomosis after distal gastrectomy. The surgical procedures, bleeding sites, and methods of hemostasis are shown in Table 2. Anastomotic hemorrhage occurred in $0.6 \%$ (5 of 878) of patients after distal gastrectomy, $1.4 \%$ ( 1 of 72 ) after proximal gastrectomy, and $0 \%(0 / 450)$ after total gastrectomy. The bleeding sites were: the transection line of the stomach using a linear stapler $(n=1)$; gastroduodenostomy using a circular stapler $(n=3)$; hand-sewn gastrojejunostomy $(n=1)$; and esophagojejunostomy using a circular stapler $(n=1)$.

The rate of anastomotic hemorrhage was $0.2 \%$ ( 1 of 454) for esophagojejunostomy using a circular stapler, $0.1 \%$ ( 1 of 878$)$ for the transection line of the stomach using a linear stapler, $0.7 \%$ (3 of 410$)$ for gastroduodenostomy using a circular stapler, and $0.5 \%$ (1 of 202) for hand-sewn gastrojejunostomy.

\section{Methods of treatment}

One patient underwent reoperation for anastomotic hemorrhage without endoscopic therapy. This patient underwent a Billroth I gastroduodenostomy using a circular stapler following distal gastrectomy. The anastomosis was resected, and manual resuturing was performed, with reconstruction by Billroth II gastrojejunostomy.

The other patients achieved complete hemostasis with endoscopic treatment. Endoscopic views of case 3 (case number as shown in Table 2) are shown in Fig. 1. The operation performed was a Billroth I gastroduodenostomy using a circular stapler following distal gastrectomy. Immediately after the surgery, fresh red blood drained from the nasogastric tube, and the total amount of drainage up to $2.5 \mathrm{~h}$ after the operation was $150 \mathrm{ml}$. The patient developed hypotension, and endoscopic hemostasis was attempted. The bleeding site was considered to be the posterior wall of the gastroduodenostomy, and complete hemostasis was achieved using endoscopic clip.

Endoscopic views of the esophagojejunostomy anastomosis in jejunal interposition following proximal gastrectomy are shown in Fig. 2 (case 4). Fresh red blood

Table 1. Surgical procedures and incidence of anastomotic bleeding according to anastomotic procedure

\begin{tabular}{lcccc}
\hline & & \multicolumn{2}{c}{ Stapling } & \\
\cline { 3 - 4 } & Hand suture & Circular stapler & Linear stapler & Total \\
\hline Distal gastrectomy & & & & $5 / 878$ \\
$\quad$ Billroth I & $0 / 40$ & $4 / 410$ & - & \\
$\quad$ Billroth II & $0 / 86$ & - & - & \\
$\quad$ Roux-en-Y & $1 / 202$ & $0 / 92$ & $0 / 48$ & $1 / 72$ \\
Proximal gastrectomy & - & $0 / 67$ & - & \\
$\quad$ Esophagogastrostomy & - & $1 / 5$ & - & 0 \\
$\quad$ Jejunal interposition & - & $0 / 450$ \\
Total gastrectomy & $0 / 1$ & $0 / 24$ & - & \\
$\quad$ Roux-en-Y & - & & - & \\
$\quad$ Double tract & & & &
\end{tabular}

Table 2. Surgical procedure, type of anastomosis, site of bleeding, and method of hemostasis

\begin{tabular}{llllll}
\hline Case no. & Type of gastrectomy & Reconstruction & Anastomosis & Site of bleeding & Hemostaticprocedure \\
\hline 1 & DG & Billroth I & CS & Gastroduodenostomy & Operation \\
2 & DG & Billroth I & CS & Gastroduodenostomy & Endoscopy \\
3 & DG & Billroth I & CS & Gastroduodenostomy & Endoscopy \\
4 & PG & Interposition & CS & Esophagojejunostomy & Endoscopy \\
5 & DG & Roux-en-Y & HS & Gastrojejunostomy & Endoscopy \\
6 & DG & Billroth I & CS & Gastroduodenostomy & Endoscopy \\
\hline
\end{tabular}

DG, distal gastrectomy; PG, proximal gastrectomy; CS, circular stapler; HS, hand suture 

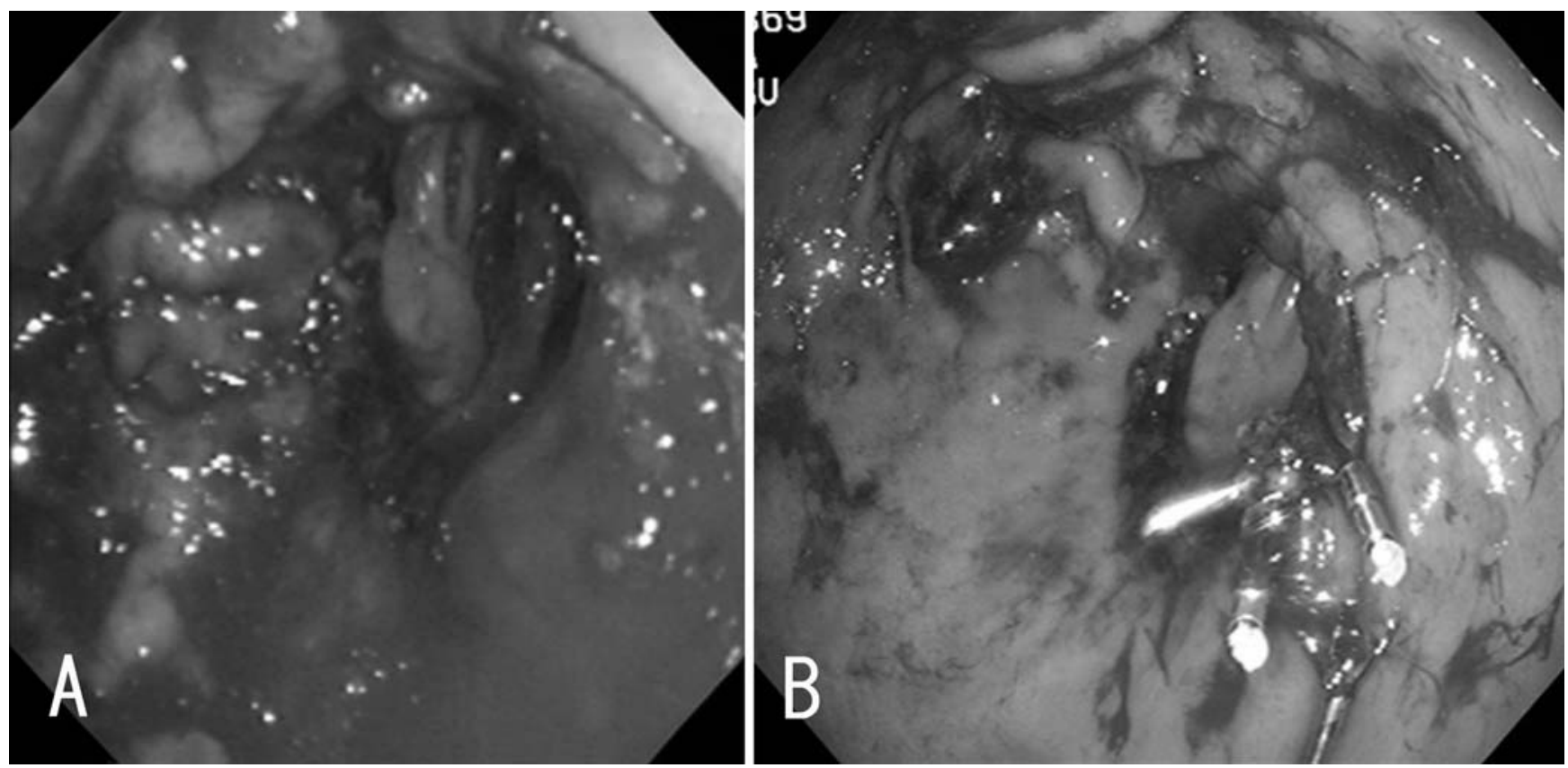

Fig. 1. A Endoscopic view of gastroduodenostomy with active bleeding from the posterior wall. B Endoscopic view of gastroduodenostomy after hemostasis using endoscopic clips
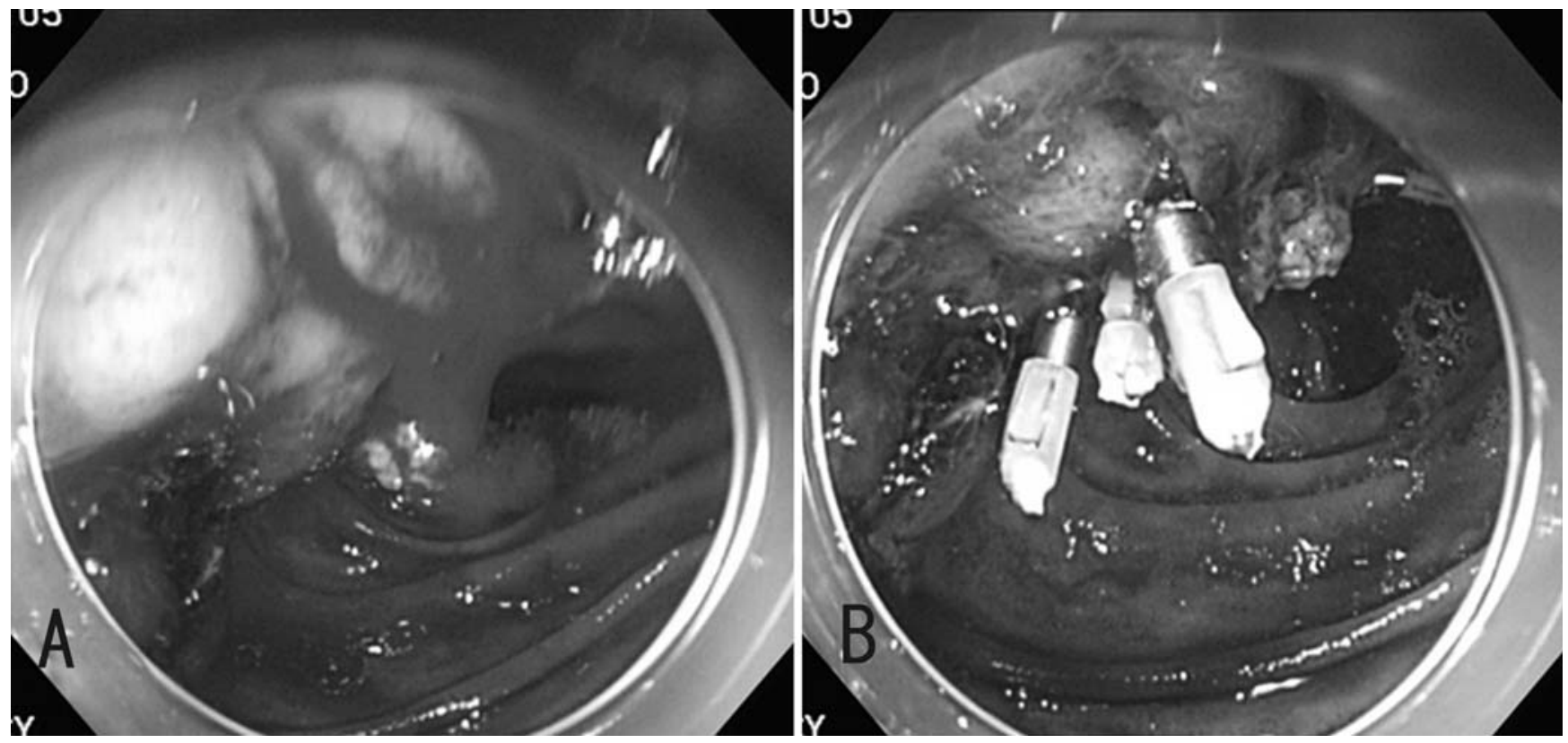

Fig. 2. A Endoscopic view of esophagojejunostomy with active bleeding. B Endoscopic view of esophagojejunostomy after hemostasis using endoscopic clips

coming from the nasogastric tube was noted after surgery, and the total amount of drainage up to $6.5 \mathrm{~h}$ after the operation was $140 \mathrm{ml}$; there was no sign of increased bleeding from the intraabdominal drain. On endoscopy, active bleeding was observed from the esophagojejunostomy. Complete hemostasis was achieved using endoclips.
The physical signs and clinical findings of the patients are listed in Table 3. The typical sign of anastomotic hemorrhage was increasing bloody drainage from the nasogastric tube, but in one patient, the blood pressure decreased and the heart rate increased without a marked increase in output from the nasogastric tube (case 4). In one patient, a small amount of fresh red blood drained 
Table 3. Clinical courses from gastrectomy to hemostasis

\begin{tabular}{|c|c|c|c|c|c|c|c|c|}
\hline $\begin{array}{l}\text { Case } \\
\text { no. }\end{array}$ & $\begin{array}{l}\text { Method of } \\
\text { hemostasis }\end{array}$ & $\begin{array}{l}\text { Postoperative } \\
\text { hemoglobin } \\
\text { level (mg/dl) }\end{array}$ & $\begin{array}{c}\text { Minimum } \\
\text { hemoglobin } \\
\text { level }(\mathrm{mg} / \mathrm{dl})\end{array}$ & $\begin{array}{c}\text { Interval } \\
\text { between } \\
\text { operation and } \\
\text { hemostasis }(\mathrm{h})\end{array}$ & $\begin{array}{l}\text { Bleeding } \\
\text { from NG } \\
\text { tube }(\mathrm{ml})\end{array}$ & $\begin{array}{l}\text { Minimum } \\
\text { blood pressure } \\
(\mathrm{mmHg})\end{array}$ & $\begin{array}{l}\text { Maximum } \\
\text { heart rate } \\
\quad(/ \mathrm{min})\end{array}$ & $\begin{array}{c}\text { Blood } \\
\text { transfusion }\end{array}$ \\
\hline 1 & Operation & 10.7 & 8.2 & 7 & 330 & $45 / 32$ & 125 & + \\
\hline 2 & Endoscopy & 9.6 & 8.3 & 2 & 390 & $99 / 58$ & 67 & - \\
\hline 3 & Endoscopy & 11.8 & 11.1 & 2.5 & 150 & $78 / 45$ & 70 & - \\
\hline 4 & Endoscopy & 13.9 & 10.8 & 6.5 & 140 & $82 / 48$ & 135 & + \\
\hline 5 & Endoscopy & 12.0 & 7.5 & 3 & 490 & $88 / 56$ & 97 & - \\
\hline 6 & Endoscopy & 12.9 & 12.1 & 46 & 660 & $100 / 58$ & 80 & - \\
\hline
\end{tabular}

NG-tube, nasogastric tube

Table 4. Clinical courses after hemostasis

\begin{tabular}{|c|c|c|c|c|c|c|}
\hline Case no. & $\begin{array}{l}\text { Hemostatic } \\
\text { procedure }\end{array}$ & UGI study & Oral intake & Discharge & $\begin{array}{c}\text { Delayed adverse } \\
\text { events }\end{array}$ & $\begin{array}{c}\text { Blood } \\
\text { transfusion }\end{array}$ \\
\hline 1 & Operation & POD7 & POD7 & POD56 & DGE & + \\
\hline 2 & Endoscopy & POD5 & POD5 & POD10 & & - \\
\hline 3 & Endoscopy & POD4 & POD4 & POD14 & & - \\
\hline 4 & Endoscopy & POD5 & POD5 & POD25 & Intraabdominal abscess & + \\
\hline 5 & Endoscopy & POD4 & POD20 & POD30 & DGE & + \\
\hline 6 & Endoscopy & POD4 & POD4 & POD12 & & - \\
\hline
\end{tabular}

UGI study, upper gastrointestinal study; POD, postoperative day; DGE, delayed gastric emptying

intermittently without any changes in the vital signs, and endoscopic hemostasis was achieved 3 days after the operation. Venous bleeding from the transection line of the stomach using a linear stapler was observed on endoscopy in one patient (case 6).

\section{Adverse events after hemostasis}

The patients' clinical courses after hemostasis are shown in Table 4. No rebleeding occurred in these six patients. Two patients had delayed gastric emptying, and one patient developed an intraabdominal abscess after the hemostatic treatment; no patients developed anastomotic leakage. The patient who underwent relaparotomy started oral intake following a postoperative upper gastrointestinal (UGI) series 7 days after the operation. This patient developed delayed gastric emptying; he was treated by fasting, and he was discharged 56 days after the initial operation. The five patients who underwent endoscopic hemostasis had postoperative UGI series done 4-5 days after hemostatic treatment and started oral intake. Of these five patients, two had adverse events. One patient developed an intraabdominal abscess, and he was discharged 25 days after the initial operation. The other patient developed delayed gastric emptying and was discharged 30 days after the initial operation. It is not likely that the delayed gastric emptying was related to the endoscopic treatment. However, the endoscopic treatment may have induced microperforation of the anastomosis and intraabdominal abscess formation. The three patients without adverse events following hemostasis were discharged on days 10-14 after the initial operation. Three patients received blood transfusions because of anemia due to the anastomotic hemorrhage.

The associations between clinical factors before the operation and the presence or absence of anastomotic hemorrhage are summarized in Table 5. There were no significant differences between the groups with respect to sex, age, and preoperative hemoglobin level. In the entire cohort, there were 195 patients who were taking anticoagulant drugs, but all of them stopped the anticoagulant medication at least 7 days before the operation. There was no significant difference in the incidence of anastomotic hemorrhage between those taking and those not taking anticoagulant medication.

Operating time, blood loss during the operation, surgical procedure, the extent of lymph node dissection, and the curative potential of gastric resection are shown in Table 6. The definition of the extent of lymph node dissection was based on the Guidelines for diagnosis and treatment of carcinoma of the stomach of the Japanese Gastric Cancer Association [12], and the definition of the curative potential of gastric resection was based on the Japanese classification of gastric carcinoma [13]. The parameters of operating time, blood loss during the operation, surgical procedure, and the curative potential of gastric resection were not significantly different 
Table 5. Relationship between patient characteristics before gastrectomy and anastomotic hemorrhage

\begin{tabular}{lccc}
\hline & \multicolumn{2}{c}{ Anastomotic hemorrhage } & \\
\cline { 2 - 3 } & Present & Absent & $P$ value \\
\hline Age (years) & $62.8 \pm 17.0$ & $64.5 \pm 10.9$ & NS \\
Sex & 4 & 935 & \\
$\quad$ Male & 2 & 459 & NS \\
$\quad$ Female & 4 & 191 & \\
Anticoagulant medication & 2 & 1203 & NS \\
$\quad$ Present & & $13.2 \pm 2.1$ & NS \\
$\quad$ Absent & $14.4 \pm 1.6$ & &
\end{tabular}

Table 6. Relationship between operative procedure and anastomotic hemorrhage

\begin{tabular}{|c|c|c|c|}
\hline & \multicolumn{2}{|c|}{ Anastomotic hemorrhage } & \multirow[b]{2}{*}{$P$ value } \\
\hline & Present & Absent & \\
\hline Operating time (min) & $175 \pm 49$ & $207 \pm 62$ & NS \\
\hline Blood loss during operation (g) & $293 \pm 150$ & $396 \pm 362$ & NS \\
\hline \multicolumn{4}{|l|}{ Type of gastrectomy } \\
\hline Distal & 5 & 873 & \\
\hline Proximal & 1 & 71 & \\
\hline Total & 0 & 450 & NS \\
\hline \multicolumn{4}{|l|}{ Extent of lymph node dissection } \\
\hline$\leq \mathrm{D} 1$ & 2 & 82 & \\
\hline $\mathrm{D} 1+\alpha, \beta$ & 4 & 767 & \\
\hline$\geq \mathrm{D} 2$ & 0 & 545 & 0.007 \\
\hline \multicolumn{4}{|c|}{ Curative potential of gastric resection } \\
\hline A & 5 & 911 & \\
\hline $\mathrm{B}$ & 0 & 306 & \\
\hline $\mathrm{C}$ & 1 & 177 & NS \\
\hline
\end{tabular}

between patients with and without anastomotic hemorrhage. However, there was a significant difference in the extent of lymph node dissection between the two groups. There were 545 patients who underwent D2 or greater extended lymph node dissection. Of these 545 patients, none had anastomotic hemorrhage.

The associations between the clinical course after hemostasis and the presence or absence of anastomotic hemorrhage are summarized in Table 7.

There was no significant difference in the length of postoperative hospital stay between patients with and without anastomotic hemorrhage, but the proportion of patients who needed blood transfusion was significantly higher in those with anastomotic hemorrhage. Delayed gastric empting and intraabdominal abscess occurred as complications after hemostasis. The incidence of delayed gastric emptying was significantly higher in the patients with anastomotic hemorrhage. However, of the two patients with delayed gastric emptying, one had undergone reoperation, and another required endoscopic intervention. Therefore, we cannot conclude that anastomotic hemorrhage leads to delayed gastric emptying.

\section{Discussion}

Anastomotic hemorrhage, compared with leakage or stricture, is a relatively rare complication following gastrectomy, and most cases are self-limited. However, when continuous hemorrhage occurs, it is life-threatening if not treated immediately. In the literature, the rate of anastomotic hemorrhage has been reported to be between $0 \%$ and $2.0 \%$ [1-9]. The great majority of studies reporting complications after gastric surgery did not focus on anastomotic hemorrhage. There are some reports dealing with the management of anastomotic bleeding after gastric bypass surgery for severely obese patients to whom antithrombotics were given to prevent deep venous thrombosis [14-19], but few reports have dealt with the management of anastomotic hemorrhage following gastrectomy for gastric 
Table 7. Relationship between clinical course after hemostasis and anastomotic hemorrhage

\begin{tabular}{lcrr}
\hline & \multicolumn{2}{c}{ Anastomotic hemorrhage } & \\
\cline { 2 - 2 } & Present & Absent & $P$ value \\
\hline Complication after hemostasis & & & \\
$\quad \begin{array}{l}\text { Intraabdominal abscess } \\
\quad \text { Present }\end{array}$ & 1 & 48 & \\
$\quad \begin{array}{l}\text { Absent } \\
\text { Delayed gastric emptying }\end{array}$ & 5 & 1346 & NS \\
$\quad$ Present & 2 & 14 & \\
$\quad$ Absent & 4 & 1380 & $<0.001$ \\
Postoperative hospital stay (days) & $24.3 \pm 17.0$ & $15.7 \pm 13.3$ & NS \\
Blood transfusion after operation & 3 & 91 & \\
$\quad$ Present & 3 & 1303 & $<0.001$ \\
$\quad$ Absent & & & \\
\hline
\end{tabular}

NS, not significant

cancer [10]. Fischer [11] reported a case of bleeding from the anastomosis using a linear stapler after gastrectomy for duodenal ulcer treated by reoperation. Umano et al. [10] reported three cases of anastomotic bleeding following esophagojejunostomy or gastroduodenostomy, which were treated by endoscopic microwave coagulation therapy. In many cases of anastomotic bleeding after gastric bypass surgery, epinephrine injection and/or heater probe cauterization was used for endoscopic hemostasis [14, 17, 18]. Tang et al. [19] reported a successful case of endoscopic hemostasis using endoclips for anastomotic bleeding after gastric bypass surgery. Guo et al. [20] reported that, in $92.5 \%$ of patients with bleeding from peptic ulcers, permanent hemostasis was achieved using endoscopic clips. Endoscopic intervention is certainly noninvasive compared to reoperation. In the present series, endoclips were used for endoscopic hemostasis, and complete hemostasis was achieved in all five patients so treated. Endoscopic examination is very useful for investigating anastomotic bleeding, because we can identify and localize the source of hemorrhage, treat the bleeding, and estimate the risk of rebleeding [21]. In addition to endoscopic hemostasis, superselective arterial embolization has been shown to be useful for treating gastrointestinal bleeding [22]. However, there is a possibility of anastomotic leakage after arterial embolization, because of decreased arterial blood supply to the anastomosis. Therefore, we should perform endoscopic examination and consider endoscopic therapy when the diagnosis is anastomotic bleeding; in fact, endoscopic hemostasis might have been more appropriate for our initial patient treated by reoperation.

Hemorrhage has been defined as significant bleeding $(>100 \mathrm{ml} / \mathrm{h}$ ) in the immediate postoperative period that required emergency reoperation or hemodynamic resuscitation [23]. The onset of anastomotic hemor- rhage usually occurs within $12-24 \mathrm{~h}$ postoperatively, and bleeding is often aggressive, with the development of hematemesis, melena, tachycardia, and hypotension [19]. In our series, bloody drainage from the nasogastric tube was observed several hours after the operation in four patients. Anastomotic hemorrhage probably occurs immediately after operation. Minor bleeding of the anastomosis is usually self-limited and can be treated conservatively.

We treated six patients with anastomotic hemorrhage, shown by tachycardia, hypotension, and increased bloody drainage from the nasogastric tube within a short time. In case 3, the hemoglobin level decreased slightly, and this patient developed hypotension with no increase in the heart rate. This could have been due to epidural morphine administration. However, in this patient, fresh bloody drainage from the nasogastric tube increased within a short time. We performed endoscopic examination within $2.5 \mathrm{~h}$ after the operation, and active bleeding was observed from the gastroduodenostomy on endoscopy. The necessity for endoscopic intervention should be judged based on consideration of the relevant factors, such as the amount of bloody drainage from the nasogastric tube, and the heart rate, blood pressure, and hemoglobin level.

In five of the present patients, arterial bleeding from the anastomosis was observed, but only in case 6 was venous bleeding observed. Venous bleeding occurred at the transection line of the stomach. Bleeding from the transection line could result in intraabdominal hemorrhage rather than in intraluminal hemorrhage; however, we have no previous experience of intraabdominal hemorrhage from the transection line of the stomach. Bleeding from a hand-sutured anastomosis occurred in only one patient (case 5). We performed gastrojejunostomy after gastrectomy using a single layer of Gambeestitch anastomosis. The Gambee stitch is a knotted 
suture, so it could be less effective for controlling bleeding from the suture line than a running suture for the anastomosis. In cases where the Gambee stitch is used, it is necessary to stop all bleeding from the submucosal layer of the stomach before performing the anastomosis.

In the present study, there was a significant difference in the extent of lymph node dissection between patients with and without anastomotic hemorrhage. No patients developed anastomotic hemorrhage after D2 and greater lymph node dissection. Extended lymph node dissection may decrease the blood supply of the anastomosis. Therefore, more careful hemostasis is needed when performing limited gastric resection.

Increased bright red bloody drainage from the nasogastric tube is most useful to diagnose anastomotic hemorrhage. Some investigators have noted that routine postoperative decompression with a nasogastric or nasojejunal tube is not necessary [24-30]. They reported that nasogastric or nasojejunal decompression did not reduce the incidence of postoperative gastrointestinal complications, and Akbaba et al. [25] reported that postoperative decompression with a nasogastric tube increased pulmonary complications. However, a nasogastric tube is useful for the immediate detection of bleeding from the anastomosis site.

We always observe the drainage from the nasogastric tube for 2-3 h after the operation to confirm the absence of bleeding, and then we remove the nasogastric tube immediately after the confirmation of hemostasis. However, when active bleeding is detected, we do not remove the nasogastric or nasojejunal tube.

Some reports have demonstrated an adverse effect of perioperative blood transfusion on the prognosis of patients with gastric cancer [31,32]. In the present series it was necessary to transfuse three patients with hemorrhagic shock arising from the bleeding anastomosis. The proportion of patients who needed blood transfusion was significantly higher in the group with an anastomotic hemorrhage.

Postoperative anastomotic hemorrhage could be avoided in almost all cases by visual inspection of the anastomosis and ensuring that no anastomotic bleeding occurs during the operation. However, the possibility of anastomotic hemorrhage remains, so when fresh bloody drainage from the nasogastric tube is observed we should immediately perform endoscopic hemostasis to avoid the need for blood transfusion.

\section{Conclusions}

Anastomotic hemorrhage after gastrectomy is a rare complication, but if it occurs, prompt treatment is needed. Endoscopic examination is needed, and endo- scopic therapy should be considered when anastomotic bleeding is diagnosed.

\section{References}

1. Sano T, Sasako M, Yamamoto S, Nashimoto A, Kurita A, Hiratsuka M, et al. Morbidity and mortality results from a prospective randomized controlled trial comparing D2 and extended para-aortic lymphadenectomy: Japan Clinical Oncology Group Study 9501. J Clin Oncol 2004;22:2767-73.

2. McCulloch P,Ward J, Tekkis PP. Mortality and morbidity in gastrooesophageal cancer surgery: initial results of ASCOT multicentre prospective cohort study BMJ 2003;22:1192-7.

3. Kim MC, Choi HJ, Jung GJ, Kim HH. Techniques and complications of laparoscopy-assisted distal gastrectomy (LADG) for gastric cancer. Eur J Surg Oncol 2007;33:700-5.

4. Kulig J, Popiela T, Kolodziejczyk P, Sierzega M, Szczepanik A. Standard D2 versus extended D2 (D2+) lymphadenectomy for gastric cancer: an interim safety analysis of a multicenter, randomized, clinical trial. Am J Surg 2007;193:10-5.

5. Hori S, Ochiai T, Gunji Y, Hayashi H, Suzuki T. A prospective randomized trial of hand-sutured versus mechanically stapled anastomoses for gastroduodenostomy after distal gastrectomy. Gastric Cancer 2004;7:24-30.

6. Yang HK, Lee HJ, Ahn HS, Yoo MW, Lee IK, Lee KU. Safety of modified double-stapling end-to-end gastroduodenostomy in distal subtotal gastrectomy. J Surg Oncol 2007;96:624-9.

7. Tanimura S, Higashino M, Fukunaga Y, Kishida S, Nishikawa M, Ogata A, et al. Laparoscopic distal gastrectomy with regional lymph node dissection for gastric cancer. Surg Endosc 2005;19: $1177-81$.

8. Kim CB, Suh KW, Moon JI, Min JS. Roux-en-Y end-to-side esophagojejunostomy with stapler after total gastrectomy. Yonsei Med J 1993;34:334-9.

9. Pedrazzani C, Marrelli D, Rampone B, De Stefano A, Corso G, Fotia G, et al. Postoperative complications and functional results after subtotal gastrectomy with Billroth II reconstruction for primary gastric cancer. Dig Dis Sci 2007;52:1757-63.

10. Umano Y, Horiuchi T, Inoue M, Shono Y, Oku Y, Tanishima H, et al. Endoscopic microwave coagulation therapy of postoperative hemorrhage from a stapled anastomosis. Hepatogastroenterology 2005;52:1768-70.

11. Fischer MG. Bleeding from stapler anastomosis. Am J Surg 1976;131:745-7.

12. Japanese Gastric Cancer Association. Guidelines for diagnosis and treatment of carcinoma of the stomach (in Japanese). Tokyo: Kanehara; 2004.

13. Japanese Gastric Association. Japanese classification of gastric carcinoma. 2nd English edition. Gastric Cancer 1998;1:10-24.

14. Nguyen NT, Longoria M, Chalifoux S, Wilson SE. Gastrointestinal hemorrhage after laparoscopic gastric bypass. Obes Surg 2004:14:1308-12.

15. Mehran A, Szomstein S, Zundel N, Rosenthal R. Management of acute bleeding after laparoscopic Roux-en-Y gastric bypass. Obes Surg 2003;13:842-7.

16. Bakhos C, Alkhoury F, Kyriakides T, Reinhold R, Nadzam G. Early postoperative hemorrhage after open and laparoscopic Roux-en-Y gastric bypass. Obes Surg 2009;19:153-7.

17. Fernández-Esparrach G, Bordas JM, Pellisé M, Gimeno-García AZ, Lacy A, Delgado S, et al. Endoscopic management of early GI hemorrhage after laparoscopic gastric bypass. Gastrointest Endosc 2008;67:552-5.

18. Jamil LH, Krause KR, Chengelis DL, Jury RP, Jackson CM, Cannon ME, et al. Endoscopic management of early upper gastrointestinal hemorrhage following laparoscopic Roux-en-Y gastric bypass. Am J Gastroenterol 2008;103:86-91. 
19. Tang SJ, Rivas H, Tang L, Lara LF, Sreenarasimhaiah J, Rockey DC. Endoscopic hemostasis using endoclip in early gastrointestinal hemorrhage after gastric bypass surgery. Obes Surg 2007; 17:1261-7.

20. Guo SB, Gong AX, Leng J, Ma J, Ge LM. Application of endoscopic hemoclips for nonvariceal bleeding in the upper gastrointestinal tract. World J Gastroenterol 2009;15:4322-6.

21. Mayer G, Lingenfelser T, Ell C. The role of endoscopy in early postoperative haemorrhage. Best Pract Res Clin Gastroenterol 2004;18:799-807.

22. Tan KK, Wong D, Sim R. Superselective embolization for lower gastrointestinal hemorrhage: an institutional review over 7 years. World J Surg 2008;32:2707-15.

23. Jex RK, van Heerden JA, Wolff BG, Ready RL, Ilstrup DM. Gastrointestinal anastomoses. Factors affecting early complications. Ann Surg 1987;206:138-41.

24. Doglietto GB, Papa V, Tortorelli AP, Bossola M, Covino M, Pacelli F. Nasojejunal tube placement after total gastrectomy: a multicenter prospective randomized trial. Arch Surg 2004;139: 1309-13.

25. Akbaba S, Kayaalp C, Savkilioglu M. Nasogastric decompression after total gastrectomy. Hepatogastroenterology 2004;51:1881-5.
26. Yoo CH, Son BH, Han WK, Pae WK. Nasogastric decompression is not necessary in operations for gastric cancer: prospective randomised trial. Eur J Surg 2002;168:379-83.

27. Wu CC, Hwang CR, Liu TJ. There is no need for nasogastric decompression after partial gastrectomy with extensive lymphadenectomy. Eur J Surg 1994;160:369-73.

28. Chung HY, Yu W. Reevaluation of routine gastrointestinal decompression after gastrectomy for gastric cancer. Hepatogastroenterology 2003;50:1190-2.

29. Lee JH, Hyung WJ, Noh SH. Comparison of gastric cancer surgery with versus without nasogastric decompression. Yonsei Med J 2002;43:451-6.

30. Carrère N, Seulin P, Julio CH, Bloom E, Gouzi JL, Pradère B. Is nasogastric or nasojejunal decompression necessary after gastrectomy? A prospective randomized trial. World J Surg 2007; 31:122-7.

31. Hyung WJ, Noh SH, Shin DW, Huh J, Huh BJ, Choi SH, et al. Adverse effects of perioperative transfusion on patients with stage III and IV gastric cancer. Ann Surg Oncol 2002;9:5-12.

32. Fong Y, Karpeh M, Brennan MF. Association of perioperative transfusions with poor outcome in resection of gastric adenocarcinoma. Am J Surg 1994;167:256-60. 